\title{
Achievement Emotions in Mathematics: Design and Evidence of Validity of a Self-Report Scale
}

\author{
Olimpia Gómez ${ }^{1}$, Benilde García-Cabrero ${ }^{1}$, Michael L. Hoover ${ }^{2}$, Sandra Castañeda-Figueiras ${ }^{1} \&$ Yolanda \\ Guevara Benítez ${ }^{3}$ \\ ${ }^{1}$ Faculty of Psychology, National Autonomous University of Mexico, Mexico City, México \\ ${ }^{2}$ Faculty of Education, McGill University, Montreal, Canada \\ ${ }^{3}$ Faculty of Superior Sutdies Iztacala, National Autonomous University of Mexico, Mexico City, México \\ Correspondence: Olimpia Gómez, Faculty of Psychology, Av. Universidad 3000, Circuito Exterior S/N \\ Delegación Coyoacán, Ciudad Universitaria, C.P. 04510. Ciudad de México, México. E-mail: \\ olimpiawhite@gmail.com
}

Received: March 15, 2020 Accepted: August 25, 2020 Online Published: September 24, 2020

doi:10.5539/jel.v9n5p233 URL: https://doi.org/10.5539/jel.v9n5p233

\begin{abstract}
The Inventory of Emotions Experienced by Adolescents when Solving Mathematical Tasks (INETAM, for its acronym in Spanish), measures four influential emotions related to Math performance: Enthusiasm, Frustration, Enjoyment, and Boredom. Content validity, construct validation and item calibration analyses were performed to obtain evidence of its validity, using a sample of 448 adolescents enrolled in ninth grade. Factor analysis showed adequate reliability coefficients and fit indices. Calibration analysis showed that the items are highly informative and discriminate between response levels. Regression analysis indicated that emotions are predictors of math achievement. INETAM is solid psychometrically, suitable for measuring academic emotions of adolescents, and can contribute to improve our understanding of their influence on academic achievement in mathematics.
\end{abstract}

Keywords: academic emotions, adolescents, assessment, mathematical tasks

\section{Introduction}

In Mexico, the results of national and international standardized educational assessments have been far from the expected. In PISA 2015, Mexican students were on average 77 points below the OECD average in Science; 70 average points below in reading, and 85 average points below in math. Only $0.6 \%$ of students reached the highest performance categories (levels 5 and 6$)$, while $33 \%$ were at the lowest ( 0 and 1$)$ levels of achievement (OECD, 2016). A similar situation occured in PISA 2018: Mexican students obtained around 80 points less than the OECD average in math, reading and science (OECD, 2019).

The same results are present in national evaluations such as PLANEA (Plan Nacional para la Evaluación de los Aprendizajes [National Plan for the Evaluation of Learning]), which is a yearly Mexican assessment program that evaluates Mexican students' achievement in language and comunication, mathematics and social and emotional skills (INEE, 2013). The 2017 PLANEA results in mathematics showed that $64.5 \%$ of high school Mexican students performed at level 1, the lowest achievement level measured by the test, which corresponds to an insufficient attainment of the country's national curriculum's key learning goals (INEE, 2017).

In order to better understand the effect of individual, maleable variables, such as emotions in academic learning, performance and achievement, researchers around the world have begun to focus on emotions, both positive and negative (Villavicencio \& Bernardo, 2015), like boredom, hoplessness, anger, anxiety, enjoyment, pride and relief (Peixoto et al., 2015). In Mexico, the recent emphasis of the New Educational Model (SEP, 2017) on socioemotional skills, has resulted in the need to design valid and reliable instruments to measure social and affective variables, such as achievement emotions, that occur in educational contexts (Pekrun, 2006).

\section{Theoretical Background}

\subsection{Achievement Emotions}

Emotions are reactions to environmental stimuli, through different response systems, to provide information about the environment, and to influence it according to the organism's needs (Gross \& Barrett, 2011). Response 
systems include: Subjective experience, defined as the appreciation of the situation and feelings; facial, body and verbal expression; and peripheral physiological responses, such as heart rate and breathing (Mauss \& Robinson, 2009).

Depending on the participant's experience, emotions can be categorized as positive or negative (Levenson, 2011), by whether they trigger pleasurable or unpleasant bodily sensations. In addition, an emotion can activate or deactivate the peripheral physiological responses (Scherer, 2005); for instance, an increase in breathing frequency or heart rate, as well as specific facial configurations (Ekman et al., 2002). These mechanisms both prepare the organism and facilitate necessary actions to respond to stimuli and situations of everyday life. Because all emotions have three basic characteristics, they are often classified by: their valence, positive versus negative; their level of activation, high or low; and/or their specific facial expression (Nielsen \& Kaszniak, 2007). Psychological development and culture define stimuli that trigger certain emotions as well as what we think and do when expressing an emotion (Haro et al., 2013). Thus, the context, understood as the moment and the situation in which an emotion occurs, should also be considered as a factor intimately related to emotions' elicitation. Accordingly, emotions can be considered as discrete, as well as domain-dependent phenomena (Goetz et al., 2006).

The emotions experienced in the school context, which influence the learning by and academic performance of students have been called academic emotions (Pekrun \& Linnenbrink-García, 2012) or achievement emotions (De la Fuente, 2014). Other types of emotions that occur in the school context are epistemic emotions, related to the information processing and knowledge acquisition; topic emotions, triggered by the content or the subject of the academic material; and social emotions, directed to other people who participate in the learning environment (Pekrun \& Linnenbrink-Garcia, 2012).

Pekrun and his collaborators (Pekrun et al., 2011) have developed a taxonomy of academic emotions, which distinguishes them by object, level of activation, value assigned to the academic activity, and degree of perceived control over it (see Table 1).

Table 1. Pekrun Goetz, Frenzel, Barchfeld and Perry (2011), Taxonomy of academic emotions

\begin{tabular}{|c|c|c|c|c|}
\hline Object & Activation & Value & Academic emotions & Control \\
\hline \multirow[t]{5}{*}{ Prospective } & Activating & Positive (success) & Hope & Medium \\
\hline & & & Anticipatory joy & High \\
\hline & & Negative (failure) & Anxiety & Medium \\
\hline & Deactivating & Positive (success) & Anticipatory relief & High \\
\hline & & & Hopelessness & Low \\
\hline \multirow[t]{9}{*}{ Retrospective } & Activating & & Joy & Irrelevant \\
\hline & & & Pride & Personal \\
\hline & & & Gratitude & Other \\
\hline & & Negative (failure) & Shame & Personal \\
\hline & & & Anger & Other \\
\hline & Deactivating & Positive (success) & Calm & Not mentioned \\
\hline & & & Relief & Not mentioned \\
\hline & & Negative (failure) & Sadness & Irrelevant \\
\hline & & & Disappointment & Not mentioned \\
\hline \multirow[t]{5}{*}{ Task } & Activating & Positive (success) & Enjoyment & High \\
\hline & & Negative (failure) & Tension & High \\
\hline & & & Frustration & Low \\
\hline & Deactivating & Positive (success) & Relaxation & Not mentioned \\
\hline & & Negative (failure) & Boredom & High/Low \\
\hline
\end{tabular}

Note. Personal elaboration from different sources.

Emotions' impact on academic achievement depends on the object or focus to which they are directed (Pekrun \& Linnenbrink-Garcia, 2012). Task emotions (enjoyment, anger, tension, frustration, relaxation and boredom) have a stronger impact on learning, performance and achievement of the activity in which the student is engaged at that moment in time. Students may experience anticipatory joy, if they know that they will face an academic activity that has a positive value, either to achieve their goals or to improve their learning, and over which they feel they have high control (Pekrun, 2006).

\subsection{Emotions and Academic Performance in Mathematics}

Several studies have identified a wide range of emotions that have important effects on academic performance 
(Harley, 2014; Martínez-Sierra \& García-González, 2017), indicating that positive emotions tend to improve academic performance as well as the reverse (Paoloni \& Vaja, 2013). However, it has been found that negative emotions can have an ambivalent effect; for example, shame can generate extrinsic motivation oriented to achievement and avoidance of failure, improving academic performance in some instances (Sánchez Rosas et al., 2011), while anxiety might be helpful in focussing attention (Grills-Taquechel et al., 2013).

Most research on emotions related to math focus on anxiety and the effect of other negative emotions, while positive emotions have received little attention (Di Leo et al., 2017; Mars et al., 2017; Pekrun et al., 2014). Most findings indicate that positive activating emotions, such as enjoyment and pride, are positively associated with math achievement (Ahmed et al., 2013; Villavicencio \& Bernardo, 2015), and negative emotions such as boredom, anxiety (Ahmed et al., 2013), anger (Peixoto et al., 2015) and hopelessness (Burić \& Sorić, 2012) are negatively related with math achievement. Kim, Park and Cozart (2014) examined the effect of motivational, affective, and cognitive process factors on math achievement in an online mathematic course. They found that anger, boredom, and enjoyment were the strongest predictors of math achievement.

According to Pekrun and Linnenbrink-Garcia (2012), the emotions most associated with academic performance in mathematics are enthusiasm, enjoyment, anxiety, frustration and boredom. Enthusiasm and enjoyment are considered positive emotions, both inducing pleasurable somatic sensations; the former, with a higher level of activation of the peripheral nervous system and bodily responses than the latter. Anxiety, frustration and boredom are defined as negative emotions (associated with unpleasant somatic sensations), with boredom being considered an emotion of low activation, because it diminishes somatic responses and sensations (Pekrun, 2006).

The emotions mentioned thus far have been widely studied, especially anxiety and frustration, however, researchers have not distinguished them by the object to which they are directed. Goetz et al. (2003) recommend considering the distinction between anticipatory and prospective emotions to clarify the effect of these emotions on different moments or situations related to learning and achievement. According to this distinction, anxiety is considered an anticipatory emotion, and, as such, it would have to be included in studies whose purpose is to understand how emotions that appear before the situation occurs affect student's achievement.

The effect of academic emotions on performance has also been approached from broader conceptual frameworks, treating them as mediating variables. For example, emotions mediate the effect of self-concept beliefs and attitudes towards mathematics, over academic achievement in mathematics (Hannula, 2002). Furthermore, emotional dispositions can influence the attitudes towards a mathematical task, depending on the student's perceived competence and interpretation of the academic situation (Di Martino \& Zan, 2011). Therefore, to better understand the impact of emotions on academic performance, it would be necessary to relate emotions with other constructs, both affective and cognitive, such as attitudes or self-efficacy beliefs (Zan et al., 2006). Relating emotions to other constructs could lead to the development of comprehensive theoretical networks and models to explain academic learning, performance and achievement by individual variables that can be both meassured and modified in order to develop better educational strategies to improve our student's achievement.

\subsection{Measurement of Achievement Emotions}

The most widely used instrument for measuring academic emotions is the Achievement Emotions Questionnaire (AEQ; Pekrun et al., 2011). This questionnaire has been translated to several languages (Frenzel et al., 2007; Pekrun \& Bühner, 2014), and adapted for different populations, for example, elementary school children (Lichtenfeld et al., 2012) and pre-adolescents (Peixoto et al., 2015). These studies have shown empirical evidence of its validity and reliability. Spanish adaptations of the AEQ have been tested with samples of junior high school, high school and university students, both in Spain (Paoloni \& Vaja, 2013) and in Argentina (Paoloni et al., 2014). The Spanish adaptations of this test have demonstrated acceptable levels of consistency.

Studies that explore the influence of emotions, specifically in mathematics achievement, mainly use the subscales of the AEQ to measure the emotions of interest and correlate the results with academic scores in mathematics (Frenzel et al., 2007; Kleine et al., 2005; Ahmed et al., 2013). Researchers also use the Academic Emotions Questionnaire-Mathematics (Math-AEQ), which measures mathematics-related enjoyment, pride, anxiety, anger, and shame, for example: "I enjoy my math classes", "During a math test, I worry that I will get a bad grade", or "I am ashamed that I cannot answer my math teacher's questions well", in three different situations (instruction, homework and testing) (Frenzel et al., 2007).

Although AEQ and Math-AEQ have shown strong psychometric properties with Spanish-speaking university students, it is important to consider that emotions have a large cultural component (Peterson, 2006). In addition, the emotional conciousness needed to recognize, name and report emotions is a developmental achievement (Valiente \& Swanson, 2012). Furthermore, with the exception of anxiety and frustration, there is a lack of 
associations between emotions and math, mainly because researchers have focused on negative emotions (Villavicencio \& Bernardo, 2015), limiting our knowledge of the effect of positive emotions in performance and achievement. There are relatively few studies regarding emotion-measurement by self report because of the difficulty to theoretically and methodologicaly distinguish between "raw emotions" and "conscious emotions" (Northoff, 2012). Finally, studies that aim to measure emotions have to elicit them first, in order to produce a correct meassurement (Nielsen \& Kasniak, 2007).

Therefore, when meassuring emotions, it is important to consider the type of emotion (academic, epistemic, topic, social, etc.), to take into account the emotional components significant to the aim of the study, and balance those components (valence, activation, expression, tendency to action, intensity, etc.), as well as take into account the context, age and other caracteristics of the participants.

The present study was designed to develop and test the psychometric validity of a self-report scale to measure four achievement emotions - two positive and two negative, both activating and deactivating: Enjoyment, Enthusiasm, Frustration and Boredom - with a sample of adolescent Mexican students. These emotions have shown to have an important impact in achievement and performance because they appear while the student is solving the task (Pekrun \& Linnenbrink-Garcia, 2014).

\section{Method}

\subsection{Study Phase I. Development and Pilot Testing}

Based on the review of the literature about the types, components and dimentions of emotions, 80 items were developed: five items for each component (valence, activation, tendency to action and intensity) of each of the four emotions under study: Enthusiasm, Enjoyment, Frustration and Boredom. To strengthen the psychometric properties of the instruments from the beginning, a validation and piloting process was included, which ensured that the construct was being measured properly and that the items were clear and consistent with the theory (Van Petegem et al., 2008).

\section{INETAM's content validation and Revision}

Five experts in psychological development, psychological measurement, and emotions, scored the initial items using a Likert-type rating scale with four response options (nothing, something, a lot, and completely), and four dimensions: clarity (the items' question is clearly understadable), relevance (the item is useful to measure the dimension), congruence (the item is highly related to the dimension) and sufficiency (the number of items is sufficient to measure the dimension).

\section{Results}

\section{Content validity}

Experts' validation was performed in presence, which permited the necessary corrections with the judges. $40 \%$ of the original 80 items were modified to increase their clarity or congruence. 10 items from subscales frustration and enjoyment were eliminated because they were considered by the experts as very similar to others or because they were not highly consistent, or were rated as irrelevant (two items from enjoyment and eight from frustration). A post-content validation version of the scale was integrated with 70 items, 20 for enthusiasm, 12 for frustration, 18 for enjoyment and 20 for boredom, including the sub dimensions of valence, activation, tendency to action and intensity. Items were constructed using a five-point Likert-type response scale: $1=\mathrm{Not}$ like me, 2 =Very little like me, $3=$ Like me, $4=$ Very much like me, $5=$ Exactly like me.

\subsection{Pilot Study}

\section{Participants}

A total of 354 adolescents participated in the pilot study, of whom 52.8\% were males, with ages ranging from 13 to 16 years $(M=14.03, S D=0.52)$. Students were enrolled in the ninth grade in four public high schools in Mexico City.

\section{Data analysis}

Skewness and kurtosis indices were obtained, items with values greater than 2 were eliminated (George \& Mallery, 2010). Also, the frequencies of the response scale were obtained to assess its relevance (Norman, 2010); response points with less than $1 \%$ in most of the items of the Inventory were removed. The Kaiser-Meyer-Olkin $(K M O)$ test, and the Bartlett's test of sphericity were used to test the normality of the data distribution. The sample was considered acceptable if the $K M O$ value was more than .80 and Bartlett's test $p$ value was less than .05 . To determine the construct validity of the instrument, an exploratory Factor Anlaysis (EFA) was 
conducted to determine internal consistency of the items (Chronbach \& Meehl, 1955), by using Cronbach's alpha. Also, items were grouped into factors if they produced factor loadings greater than .40. Groups with two or fewer items were eliminated (Williams et al., 2010).

\section{Result}

Construct validity

Each scale (Enthusiasm, Frustration, Enjoyment and Boredom), produced high values of sample adequacy ( $K M O$ $=0.912,0.890,0.972$, and 0.913; Bartlett's sphericity test resulted in a value of .000 in all cases), and all demonstrated high internal consistency $(\alpha=0.86,0.85,0.90,0.89)$.

A more precise factor analysis revealed that most of the items corresponding to the emotion's intensity were empirically grouped within the valence and activation subscales, so the intensitiy subscale was eliminated for all emotions. Items from other subscales were eliminated because they produced factor loadings of less than .40, mainly in the activation and tendency to action subscales. The strongest subscale was valence for all four emotions. Three items were removed from the Frustration Scale because they presented factor loadings less than 0.40 in absolute value. These items referred to three aspects: breathing, discomfort, and comparison with other equally frustrating activities. Also, the subscale tendency to action was not included in the Frustration scale. The changes led to the elimination of eight items from the enjoyment, enthusiasm and boredom scales, and four items from frustration scale.

After the pilot validation, the INETAM included 44 items: 12 items for each of the academic emotions of Enthusiasm, Enjoyment and Boredom, each with four items for the subscales of valence, activation and tendency to action; and eight items to measure Frustration, with four items each for valence and activation.

Another result to take into account was the skewness for the items: "Due to the frustration I had to get up from my seat" and "I wanted to cry", which presented a strong bias for the low values of the response scale. This could be due to the fact that these behaviors, such as getting out of one's seat or crying are not acceptable behaviors in the Mexican classroom context.

Regarding the response categories, it was observed that the category Exactly like me was almost never selected in $40 \%$ of the items, so it was eliminated, leaving only four response options: $1=$ Not like me, $2=$ A little like me, 3 $=$ A lot like me, $4=$ Very like me.

\subsection{Study Phase II. Assessing the Psychometric Properties of the Tevised INETAM}

\section{Participants}

A total of 452 ninth-grade high school students, enrolled in two public schools in Mexico City, participated in the study. The students' age ranged between 13 and 16 years old $(M=14.03, S D=0.341), 53.1 \%$ of them were male. This sample was different from the one used in the Pilot study.

\section{Variables measured}

Achievement in mathematics: Mathematics academic task. A mathematical task was included to elicit the emotions and experiences reported by students. The task was selected from the ninth-grade teacher's document "Didactic orientations and lesson plans. Block I", in which students had to solve four algebra problems of increasing difficulty. This activity was chosen because it corresponded to the activities in the curriculum at the time of the sutdy. The activity chosen had a medium level of difficulty and thus could be solved by most of the students. The task was scored using a five-value rubric developed to assess the performance level observed for each problem: inadequate, not-sufficient, low, medium, and high.

Academic emotions in mathematics were measured using the Inventory of Academic Emotions during Mathematical Tasks (Revised-INETAM) composed of 44 items: 12 items for each of the academic emotions of Enthusiasm, Enjoyment and Boredom, and 8 items to measure Frustration, with a Likert-type response scale of four options: 1 = Not like me to 4 =Very like me. To provide concurrent validity for the study, attitudes towards mathematics were also measured to correlate these results with those of the pilot test of INETAM, given that previous studies have shown that attitudes towards mathematics have a strong relationship with the emotions experienced by students when completing math tasks (Zan et al., 2006). This scale has been validated with adolescent Spanish-speaking students (Palacios et al., 2014).

Attitudes towards mathematics: Scale of Attitudes towards Mathematics (EAM by its acronym in Spanish: Escala de Actitudes hacia las Matemáticas; Palacios et al., 2014). This 37-item scale uses a five Likert-type options (from 0 to 4 ) to meaure five aspects of attitudes towards mathematics: enjoyment for mathematics, anxiety towards mathematics, perception of difficulty, perceived utility and mathematical self-concept. The scale was 
developed and validated with 4807 Spanish students from primary, junior high and high school. Cronbach's alpha for each factor ranged from .67 to .92 , with an overall coefficient of $\alpha=.93$.

\section{Procedure}

Principals of each school assigned schedules for the administration of the instruments during class time in the two last weeks of November. In the assigned classes, a researcher explained the aim of the study and read the instructions out loud, informed consent (which explained that their participation was voluntary, confidential and anonymous, and their answers would not affect them in any way) and response example, so that every student understood the response process and the importance of their participation. Students were given five minutes to solve the mathematical task, which was the mean time students needed to solve it. After completing the math task, they answered the INETAM, and during the following class period, approximately 20 minutes after they completed the first part, they were administered the EAM.

\section{Analysis of Data}

The main study data analysis consisted of the estimation of psychometric models using the Classic Test Theory (CTT) and the Items Response Theory (IRT) frameworks (Baker, 2001; Muñiz, 1994; Samejima, 1997). Models of CTT helped to identify the strength and accuracy with which each construct was measured (Muñiz, 1994). Models of IRT permited the estimation of the parameters of the items' information and difficulty, which offered additional information about the scale, in terms of its usefulness in measuring different aspects of the construct (Luna Baldazua et al., 2017). Descriptive, Exploratory and Confirmatory Factor Analyses (EFA and CFA, respectively) were conducted to explore stronger evidence of validity, assessing the latent structure of the Inventory INETAM and its deviation from the perfect model (Hoyle, 2004).

Correlation and regression analysis were performed following the method from Calleja (2009). First the inter-correlations were computed, then, variables with significant correlation indices were introduced into the regression analysis equation to evaluate causal relationships. Item calibration was assessed using both (a) discrimination and (b) level of difficulty indices (Hambleton, 2004). According to Baker (2001), discrimination parameters should be higher than .60, with low standard errors for both $a$ and $b$ parameters $(<.30)$, with ordered thresholds for $b$ and no overlap.

\section{Results}

Math activity

Descriptive statistics for the mathematical activity used are presented in Table 2 . The correlation between the score in the math activity and the course grade was moderate and significant $(r=.421, p<.01)$.

Table 2. Descriptive statistics of the Math activity used in the study

\begin{tabular}{llllllll}
\hline & $\boldsymbol{N}$ & Min & Max & Mean & SD & Skew & Kur \\
\hline Score in Math activity & 405 & 0 & 9 & 2.8 & 1.9 & .421 & -.795 \\
\hline
\end{tabular}

\subsection{INETAM}

All indices of skewness and kurtosis ranged from -1.13 to 1.73 and total-item correlation ranged from .017 to .394, providing evidence of near normal distributions of the variables (Blanca et al., 2013) and no existing problems in discriminant validity (Engellant et al., 2016). The items "I was so excited that I wanted to jump" from Enthusiasm, and "I felt the urge to punch or throw away something" from Frustration, presented skewness and kurtosis indices larger than two. Three items were in the Enjoyment and Boredom scales were eliminated from further analysis because they produced negative total-item correlations: "I felt calm during the task" $(r=-.016, p$ $<.01)$, "I felt bored while completing the exercise" $(r=-.010, p<.01)$, and "I wanted to do something else less boring" $(r=-.018, p<.01)$.

Construct validity

EFA showed good indices for every scale and subscales (see Tables 3 to 6). Enthusiasm showed a bi-factorial structure: Joy and Perseverance factors, according to the item characteristics. Enjoyment was explained by two factors, Pleasure and Commitment; and Boredom also presented a bi-factorial structure: Annoyance and Discouragement factors. Frustration was the only scale with a unidimensional structure. 
Table 3. Enthusiasm's EFA

\begin{tabular}{|c|c|c|c|}
\hline & & \multicolumn{2}{|c|}{ Factor loadings } \\
\hline & & Joy & Perseverance \\
\hline 1. & I loved the task & .803 & \\
\hline 2. & I felt very happy while solving the task & .792 & \\
\hline 3. & I experienced a lot of energy while solving the task & .776 & \\
\hline 4. & I felt really good & .764 & \\
\hline 5. & Solving the task was pleasant to me & .762 & \\
\hline & I wanted to know the right result & & .805 \\
\hline & I wanted more time to continue solving the task & & .744 \\
\hline & I wanted to make a great effort to solve the task & & .728 \\
\hline \multicolumn{2}{|r|}{ Bartlett's sphericity test } & \multicolumn{2}{|c|}{$1342.49, p<.001$} \\
\hline \multicolumn{2}{|c|}{ KMO } & \multicolumn{2}{|l|}{.864} \\
\hline \multicolumn{2}{|c|}{ Items } & 5 & 3 \\
\hline \multicolumn{2}{|c|}{ Explained variance } & 38.47 & 22.00 \\
\hline \multicolumn{2}{|c|}{ Cronbach's alpha } & .83 & .63 \\
\hline \multicolumn{2}{|c|}{ Eigen values } & 4.1 & 1.7 \\
\hline
\end{tabular}

Note. Extraction method: Principal Component Analysis. Rotation method: Varimax with Kaiser Normalization. Rotation converged in 5 iterations.

Table 4. Enjoyment's EFA

\begin{tabular}{|c|c|c|c|}
\hline & & \multicolumn{2}{|c|}{ Factor loadings } \\
\hline & & Pleasure & Commitment \\
\hline 1. & I realized I was enjoying solving the task & \multicolumn{2}{|l|}{.831} \\
\hline & I enjoyed solving the task & \multicolumn{2}{|l|}{.805} \\
\hline 3. & The task made me feel good & \multicolumn{2}{|l|}{.805} \\
\hline 4. & I enjoyed solving the excercise the same as when solving task I like & \multicolumn{2}{|l|}{.755} \\
\hline 5. & The task caught my attention & \multicolumn{2}{|l|}{.692} \\
\hline 6. & I set out to solve the task correctly & & .749 \\
\hline 7. & I set out to solve the whole task & & .720 \\
\hline 8. & I had to make an effort to understand what I had to do & & .689 \\
\hline & I wanted to solve the task correctly & & .618 \\
\hline & I experienced enough energy to solve the task & & .496 \\
\hline \multicolumn{2}{|r|}{ Bartlett's sphericity test } & \multicolumn{2}{|c|}{$1726.69, p<.001$} \\
\hline \multicolumn{2}{|c|}{$K M O$} & \multicolumn{2}{|c|}{.883} \\
\hline \multicolumn{2}{|c|}{ Items } & 5 & 5 \\
\hline \multicolumn{2}{|c|}{ Explained variance } & 34.19 & 23.99 \\
\hline \multicolumn{2}{|c|}{ Cronbach's alpha } & .86 & .73 \\
\hline \multicolumn{2}{|c|}{ Eigen values } & 4.9 & 1.3 \\
\hline
\end{tabular}

Note. Extraction method: Principal Component Analysis. Rotation method: Varimax with Kaiser Normalization. Rotation converged in 5 iterations.

Table 5. Boredom's EFA

\begin{tabular}{|c|c|c|c|}
\hline & & \multicolumn{2}{|c|}{ Factor loadings } \\
\hline & & Annoyance & Discouragement \\
\hline 1. & I felt bored while solving the exercise & .822 & \\
\hline 2. & Solving the task made me feel weak & .783 & \\
\hline 3. & I wanted to do something less boring & .772 & \\
\hline 4. & I wanted to fall asleep & .740 & \\
\hline 5. & Others may have noticed I was bored & .679 & \\
\hline 6. & I wanted to leave the task incomplete & .478 & \\
\hline 7. & I felt like I had no strength in my body & & .838 \\
\hline 8. & I felt really tired while solving the task & & 699 \\
\hline & I felt completely without energy & & .664 \\
\hline \multicolumn{2}{|c|}{ Bartlett's sphericity test } & $1303.54, p<$ & \\
\hline \multicolumn{2}{|c|}{ KMO } & .835 & \\
\hline \multicolumn{2}{|c|}{ Items } & 6 & 3 \\
\hline \multicolumn{2}{|c|}{ Explained variance } & 36.74 & 20.24 \\
\hline \multicolumn{2}{|c|}{ Cronbach's alpha } & .85 & .67 \\
\hline \multicolumn{2}{|c|}{ Eigen values } & 4.9 & 1.2 \\
\hline
\end{tabular}

Note. Extraction method: Principal Component Analysis. Rotation method: Varimax with Kaiser Normalization. Rotation converged in 3 iterations. 
Table 6. Frustration's EFA

\begin{tabular}{lll}
\hline & & Factor loadings \\
\hline 1. & The task made me feel frustration & .749 \\
$2 . \quad$ I felt tension while solving the task & .695 \\
$3 . \quad$ I felt a knot in my stomach while solving the task & .691 \\
$4 . \quad$ I had the urge to do something to stop feeling so bad & .658 \\
$5 . \quad$ I crunched my fists or teeth while solving the task & .634 \\
$6 . \quad$ I wished I was solving an easier task & .576 \\
$7 . \quad$ I experienced unpleasant sensations in my body & .573 \\
$8 . \quad$ I felt the urge to hit or throw something while solving the task & .495 \\
Bartlett's sphericity test & $653.37, p<.001$ \\
$K M O$ & .862 \\
Items & 8 \\
Explained variance & 40.75 \\
Cronbach's alpha & .79 \\
Eigen value & 3.26 \\
\hline
\end{tabular}

Note. Extraction method: Principal Component Analysis, 1 component extracted.

The factor loadings and $p$-values shown in Table 7 indicate that all items have a positive significant relationship with their corresponding latent factor. No factor loading was smaller than 0.3 in absolute value, implying that the measurement component of the latent variables in the models adequately represent the relationship between observed and latent variables (Hooper et al., 2007).

Table 7. Summary of CFA indices for each scale (asymptotically distribution, $\mathrm{N}=448$ )

\begin{tabular}{lllll}
\hline Scale (model) & $\mathrm{X}^{2}(d f, p$-value $)$ & $C F I$ & $R M S E A(90 \%$ interval confidence $)$ & SRMR \\
\hline Enthusiasm (bifactorial model) & $39.848(d f=19, p=.003)$ & .979 & $.050(.028, .071)$ & .035 \\
Frustration (unifactorial model) & $35.124(d f=19, p=.013)$ & .979 & $.044(.020, .066)$ & .026 \\
Enjoyment (bifactorial model)* & $37.639(d f=21, p=.014)$ & .990 & $.042(.019, .063)$ & .019 \\
Boredom (bifactorial model) & $38.312(d f=23, p=.024)$ & .989 & $.039(.014, .060)$ & .028 \\
\hline
\end{tabular}

Note. *It was necessary to eliminate item two of the commitment subscale: "I was prepared to do the complete exercise", because it presented a factor loading smaller than .40 and its elimination resulted in a better fit.

\section{Items Calibration}

The information and difficulty indices obtained showed that all items were highly informative of their latent variables, because all difficulty indices were greater than 1 (Hambleton, 2004). Further, they measured low, medium and high levels of the variable, as seen in $b$ values that range from -2.23 to 3.65 , corresponding to the response scale from 0 (not like me) to 4 (very like me) (see Table 8).

Table 8. Ranges of discrimination (a), difficulty (b) indices, and standard error (SE) corresponding to INETAM subscales, obtained by the method of maximum marginal likelihood

\begin{tabular}{|c|c|c|c|c|c|c|}
\hline \multirow[b]{2}{*}{ Scale } & \multirow[b]{2}{*}{ Subscale } & \multicolumn{5}{|l|}{ Index range } \\
\hline & & $a$ & $b 1$ & $b 2$ & $b 3$ & $S E$ \\
\hline \multirow[t]{2}{*}{ Enthusiasm } & Joy & 2.62 to 1.94 & -1.40 to -0.44 & 0.33 to 0.98 & 1.69 to 2.15 & .08 to .19 \\
\hline & Perseverance & 2.24 to 1.38 & -2.05 to -1.13 & -1.00 to 0.98 & 0.29 to 1.30 & .08 to .39 \\
\hline Frustration & & 2.32 to 1.04 & -1.31 to 1.47 & 0.35 to 2.38 & 1.49 to 3.65 & .08 to .55 \\
\hline \multirow[t]{2}{*}{ Enjoyment } & Pleasure & 3.16 to 1.22 & -1.06 to -0.53 & 0.36 to 0.72 & 1.36 to 1.96 & .07 to .31 \\
\hline & Commitment & 2.73 to 1.20 & -2.23 to -1.59 & -0.96 to -0.35 & 0.57 to 1.57 & .07 to .34 \\
\hline \multirow[t]{2}{*}{ Boredom } & Annoyance & 2.61 to 1.13 & -.085 to -.018 & 0.34 to 1.25 & 1.11 to 2.36 & .07 to .26 \\
\hline & Discouragement & 2.16 to 1.81 & -0.34 to 0.26 & 0.96 to 1.20 & 1.88 to 2.11 & .07 to .30 \\
\hline
\end{tabular}

Discriminant validity

Enthusiasm and Enjoyment subscales demonstrated a very strong correlation: $r=.792,(p<.001)$. Furr and Bacharach (2013) recommend suppressing one dimension if a strong covariance index appears. Thus, only the Enjoyment scale was considered in further analysis because it presented greater factor loadings and fit indices. 
Frustration and Boredom $(r=.537, p<.001)$, showed that, as expected and in congruence with the theory, significant moderate positive correlations, as well as the subscales of Annoyance and Discouragement $(r=.548$, $p<.001)$ and Pleasure with Commitment $(r=.576, p<.001)$. Likewise, factors integrated by positive emotions had significant moderate negative correlation with factors belonging to negative emotions, for example: Pleasure and Discouragement $(r=-.353, p<.001)$ or Commitment and Annoyance $(r=-.380, p<.001)$.

Convergent validity

\section{Differences by sex}

Average scores of males and females in the math academic task showed no significant differences between sexes. Regarding the academic emotions experienced by students, women reported experiencing greater Annoyance than men $\left(t_{(395)}=18.279, p<.001\right)$.

\section{Emotions and scores in mathematics}

All emotions showed significant moderate correlations with the student scores in the math task, ranging from -319 to .433 , with p-values less than .05 . The largest correlations with scores in the math task were produced for Frustration $(r=-.362, p<.01)$, Commitment $(r=.433, p<.01)$ and Discouragement $(r=-.319, p<.01)$.

\section{Emotions, attitudes towards mathematics and scores}

A correlation analysis was conducted between the measure of attitudes towards mathematics and the scales measured by the INETAM; the results produced, in most cases, significant correlations with $p$-values less than 0.01. Negative correlations were obtained between Pleasure and Commitment with the Perception of mathematical incompetence, as well as between Frustration, Annoyance and Fatigue with Enjoyment for mathematics and Mathematical self-concept. The strongest correlations were found between Pleasure and Enjoyment for mathematics $(r=.661, p<.01)$, as well as Frustration with Perception of mathematical incompetence $(r=.556, p<.01)$.

\section{Math achievement, emotions and attitudes towards mathematics}

Regression analysis was used to determine which attitudes towards mathematics and emotions significantly predict the performance in the mathematical academic task. The results of the analysis indicated that Frustration and Commitment were significant predictors of the student's performance meassured by the grades in both the activity and the subject, as well as Perception of mathematical incompetence, Mathematical self-concept and Perception of utility (see Table 9).

Table 9. Significant predictors of emotions and attitudes towards mathematics over the Score in mathematics

\begin{tabular}{lllll}
\hline & Beta $(S E)$ & $T$ & $F(d f)$ & $R^{2}(S E)$ \\
\hline Frustration & $-.199(.139)$ & $-4.589^{* * *}$ & $69.657(3,444)$ & $.32(1.56)$ \\
Commitment & $.501(.131)$ & $11.109^{* * *}$ & $* * *$ & \\
P. of mathematical incompetence & $-.449(.147)$ & $-9.18^{* * *}$ & 40.842 & $.21(1.67)$ \\
$\quad$ Mathematical self-concept & $.149(.133)$ & $3.40^{* *}$ & $(3,444) * * *$ & \\
Perception of utility & $.113(.162)$ & $2.35 *$ & & \\
Note. $* * *=p<.001$. & & & &
\end{tabular}

\section{Discussion}

The goal of this study was to explore the psychometric properties of a new self-report scale, INETNAM, to assess the academic emotions experienced by adolescent Mexican students while solving mathematical tasks, in order to provide a powerful contextualized instrument to evaluate the relationship of emotions in mathematics and performance among Mexican students. INETNAM has solid psychometric properties; it can be used with confidence to evaluate the emotions that Mexican high school students experience while performing mathematics tasks, either as a unit or separately, depending on the research focus, and can easily be adapted to assess emotions in other subjects or academic contexts. Pekrun and his coleagues have used the AEQ with students of different levels and in various academic conditions, showing the wide range of emotions that can be experienced in an academic context by university students (Pekrun, 2006). Other authors have used the AEQ subscales separately, especially the in class subscale, improving our understanding of the role that emotions play during academic performance, with younger students (Paoloni \& Vaja, 2013).

Mexican high school students experience various emotions when underaking mathematics activities, both negative and positive, activating and deactivating. The correlations between emotions and scores in mathematics 
showed that Frustration (negative activating), Commitment (positive deactivating) and Discouragement (negative deactivating) have stronger relationships with academic achievement. The regression analysis showed that it is Commitment, a positive deactivating emotion, that had the largest impact on academic achievement ( $B$ $=.501, p<.001)$.

While most studies have focused on negative emotions, like boredom (Pekrun et al., 2014), frustration (Di Leo et al., 2017) and anxiety (Mars et al., 2017), this and other studies show that positive emotions also have a strong influence on academic achievement (Villavicencio \& Bernardo, 2015) and so they should be considered in learning and teaching.

Correlation analyses corroborated other findings about the relationship between positive and negative emotions, their connection with both mathematical achievement and attitudes towards mathematics (Ahmed et al., 2013). Another clear-cut result of this study is that attitudes towards mathematics and the emotions experienced when learning mathematics are closely related, which has also been found in previous studies (Hannula, 2002).

On the other hand, positive relationships (Frustration and Discouragement with Perception of Mathematical Incompetence; Pleasure and Commitment with Enjoyment for Mathematics), as well as negative ones (Frustration, Nuisance and Delay with Mathematical Self-concept) are congruent with the literature (Di Martino $\&$ Zan, 2011) and provide a greater understanding of mathematics performance. Students who feel incompetent are more likely to experience negative emotions when performing tasks and have a worse performance; in comparison with students who have positive attitudes, positive self-concept and enjoy the activities (Nuria et al., 2006).

The results regarding gender differences are consistent with recent research studies indicating that the difference in math performance between men and women emerge in high school or college, once students begin to choose career based on their abilities and interests (Cheema \& Galluzzo, 2013). Furthermore, the nuisance experienced by women, can largely explain why they are less likely to choose careers related to mathematics (Zeldin et al., 2007).

It should be noted that the lowest correlations and with the least statistical significance were between emotions and perceptions of utility. This may be because this latter aspect of attitudes towards mathematics has more of a cognitive rather than an affective component. It would be worth exploring the relationship between the perception of utility and other cognitive variables related to the performance of mathematical activities, such as self-efficacy beliefs.

\section{Implications and Future Research}

In the future, it would be useful to test the Inventory with other Spanish-speaking populations, in concert with other instruments, to assess its convergent and discriminant validity with other variables, which could be related to different cognitive aspects, as well as to evaluate the weight of each one on academic performance in mathematics and in other subjects or academic activities. Also, it would be useful to explore which emotions have the greatest impact on academic performance and achievement, considering both their valence and activation, across different academic contexts: with younger and older students, and different subjects, such as math, science, and reading. For example: Studies are needed that explore the emotions that students experience when engaging in different school activities and how managing these emotions in class, specially, positive emotions such as enjoyment and enthusiasm, improves academic performance and achievement.

By identifying the effects of different emotions on achievement, researchers and educators can work together to develop strategies that enhance students' academic performance by encouraging positive emotions and minimizing the negative emotions that affect students' learning and performance in diverse contexts.

\section{Acknowledgement}

The present study was developed thanks to the National Council of Science and Technology of Mexico, grant number: 245404.

\section{References}

Ahmed, W., van der Werf, G., Kuyper, H., \& Minnaert, A. (2013). Emotions, self-regulated learning, and achievement in mathematics: A growth curve analysis. Journal of Educational Psychology, 105(1), 150-161. https://doi.org/10.1037/a0030160

Baker, F. (2001). The basics of item response theory. USA: ERIC Clearinghouse on Assessment and Evaluation.

Blanca, M., Arnau, J., López-Montiel, D., Bono, R., \& Bendayan, R. (2013). Skewness and Kurtosis in Real Data Samples. Methodology, 9, 78-84. https://doi.org/10.1027/1614-2241/a000057 
Burić, I., \& Sorić, I. (2012). The role of test hope and hopelessness in self-regulated learning: Relations between volitional strategies, cognitive appraisals and academic achievement. Learning and Individual Differences, 22(4), 523-529. https://doi.org/10.1016/j.lindif.2012.03.011

Calkins, S., \& Leerkes, E. (2011). Early attachment processes and the development of emotional self-regulation. In K. Vohs \& R. Baumeister (Eds.), Handbook of self-regulation: Research, theory and applications (pp. 355-373). Guilford Press.

Cheema, J., \& Galluzzo, G. (2013). Analyzing the Gender Gap in Math Achievement: Evidence from a Large-Scale US Sample. Research in Education, 90, 98-112. https://doi.org/10.7227/RIE.90.1.7

Cronbach, L. J., \& Meehl, P. E. (1955). Construct validity in psychological tests. Psychological Bulletin, 52(4), 281-302. https://doi.org/10.1037/h0040957

D’Mello, K., Lehman, B., \& Person, N. (2010). Monitoring affect states during effortful problema solving activities. International Journal of Artificial Intelligence in Education, 20(4), 361-389.

Daley, D., Renyard, L., \& Sonuga-Barke, E. (2010). Teachers' emotional expressiona about disruptive boys. British Journal of Educational Psychology, 75(1), 25-35. https://doi.org/10.1348/000709904X22269

De la Fuente, J. (2014). Introduction to Monograph: Achievement Emotions at University. Electronic Journal of Research in Educational Psychology, 12(3), 563-556.

Di Leo, I., Muis, K., Singh, C., \& Psaradellis, C. (2019). Curiosity... Confusion? Frustration! The roela and sequencing of emotions during mathematics problem solving. Contemporary Educational Psychology, 58, 121-137. https://doi.org/10.1016/j.cedpsych.2019.03.001

Di Martino, P., \& Zan, R. (2011). Attitude towards mathematics: a bridge between beliefs and emotions. ZDM Mathematics Education, 43(4), 471-482. https://doi.org/10.1007/s11858-011-0309-6

Ekman, P., Friesen, W. V., \& Hager, J. C. (2002). Facial Action Coding System. Manual and Investigator's Guide. Research Nexus.

Engellant, K., Holland, D., \& Piper, R. (2016). Assesing Convergent and Discriminant Validity of the Motivation Construct for the Technology Integration Education (TIE) Model. Journal of Higher Education Theory and Practice, 16(1), 37-50.

Frenzel, A. C., Trash, T. M., Pekrun, R., \& Goetz, T. (2007). Achievement emotions in Germany and China: A cross-cultural validation of the Academic Emotions Questionnaire-Mathematics (AEQ-M). Journal of Cross-Cultural Psychology, 38, 302-309. https://doi.org/10.1177/0022022107300276

Frenzel, A., Pekrun, R., \& Goetz, T. (2007a). Perceived learning environment and students' emotional experiences: A multilevel analysis of mathematics classrooms. Learning and Instruction, 17(5), 478-493. https://doi.org/10.1016/j.learninstruc.2007.09.001

Frenzel, A., Pekrun, R., \& Goetz, T. (2007b). girls and mathematics-A "hopeless" issue? A control-value approach to gender differences in emotions towards mathematics. European Journal of Psychology of Education, 22(4), 497-514. https://doi.org/10.1007/BF03173468

Furr, M., \& Bacharach, V. (2014). Psychometrics: An introduction. Sage.

George, D., \& Mallery, M. (2010). SPSS for Windows Step by Step: A Simple Guide and Reference (17.0 update). Pearson.

Goetz, T., Zirngibl, A., Pekrun, R., \& Hall, N. (2003). Emotions, Learning and Achievement from an Educational-Psychological Perspective. In P. En Mayring \& C. von Rhoeneck (Eds.), Learning emotions: the influence of affective factor son classroom learning (pp. 9-28). Peter Lang.

Grills-Taquechel, A., Fletcher, J., Vaughn, S., Denton, C., \& Taylor, P. (2013). Anxiety and inattention as predictors of achievement in early elementary school children. Anxiety, Stress \& Coping: An Internaational Journal, 26(4), 391-410. https://doi.org/10.1080/10615806.2012.691969

Gross, J. J., \& Barrett, L. F. (2011). Emotion generation and emotion regulation: One or two depends on your point of view. Emotion Review, 3, 8-16. https://doi.org/10.1177/1754073910380974

Hambleton, R. (2004). Theory, methods, and practices in testing for the 21st century. Psicothema, 16(4), 696-701.

Hannula, M. (2002). Attitude towards mathematics: emotions, expectations and values. Educational Studies in Mathematics, 49(1), 25, 46. https://doi.org/10.1023/A:1016048823497 
Harley, J. (2014). Measuring Emotions with an Agent-based Learning Environment (Tesis de doctorado inédita). Universidad McGill: Canadá.

Haro, I., García-Cabrero, B., \& Reidl, L. (201). Experiencias de culpa y vergüenza en situaciones de maltrato entre iguales en alumnos de secunaria. [Experiences of guilt and shame in bullying situation among high school students]. Revista Mexicana de Invesgtgación Educativa, 18(59), 1047-1075.

Hayes, A. (2013). Introduction to Mediation, Moderation and Conditional Process Analysis. The Guilford Press.

Hooper, D., Coughlan, J., \& Mullen, M. R. (2008). Structural Equation Modelling: Guidelines for Determining Model Fit. The Electronic Journal of Business Research Methods, 6, 53-60.

Hoyle, R. H. (2004). Confirmatory factor analysis. In M. Lewis-Beck, A. Bryman \& T. Liao (Eds.), Encyclopedia of social science research methods (Vol. 1, pp. 169-175). Retrieved from https://www.researchgate.net/publication/232477638_Confirmatory_Factor_Analysis/link/59a957fc458515 eafa910969/download

INEE. (2013). What is Planea? http://www.inee.edu.mx/index.php/planea

INEE. (2017). Planea. Planea. http://planea.sep.gob.mx/content/general/docs/2017/RESULTADOS_NACIONALES_PLANEA2017.pdf

Kleine, M., Goetz, T., Pekrun, R., \& Hall, N. (2005). The structure of students' emotions experienced during a mathematical achievement test. Mathematics Education, 37(3), 221-225. https://doi.org/10.1007/s11858-005-0012-6

Lee, M., \& van Black, S. (2017). Teachers' emotional labour, discrete emotions, and classroom management self-efficacy. Educational Psychology, 38(5). https://doi.org/10.1080/01443410.2017.1399199

Levenson, R. (2011). Basic Emotion Questions. Emotion Review, 3(4), 379-386. https://doi.org/10.1177/1754073911410743

Lichtenfeld, S., Pekrun, R., Stupnisky, R., Reiss, K., \& Murayama, K. (2012). Measuring students'emotions in the early years: The Achievement Emotions Questionnaire-Elementary School (AEQ-ES). Learning and Individual Differences, 22(1), 190-201. https://doi.org/10.1016/j.lindif.2011.04.009

Luna Bazaldua, D. A., Lee, Y. S., Keller, B., \& Fellers, L. (2017). Assessing the performance of classical test theory item discrimination estimators in Monte Carlo simulations. Asia Pacific Education Review, 18(4), 585-598. https://doi.org/10.1007/s12564-017-9507-4

Marsh, H. W., Pekrun, R., Parker, P. D., Murayama, K., Guo, J., Dicke, T., \& Lichtenfeld, S. (2017). Long-term positive effects of repeating a year in school: Six-year longitudinal study of self-beliefs, anxiety, social relations, school grades, and test scores. Journal of Educational Psychology, 109(3), 425-438. https://doi.org/10.1037/edu0000144

Martínez-Sierra, G., \& García-González, M. (2017). Students' Emotions in the High School mathematics Class: Appraisals in Terms of a Structure of Goals. International Journal of Science and Mathematics Education, 2(15), 349-369. https://doi.org/10.1007/s10763-015-9698-2

Martínez-Sierra, G., Arellano-García, Y., Hernández-Moreno, A., \& Nava-Guzmán, C. (2019). Daily Emotional Experiences of a High School Mathematics Teacher in the Classroom: A Qualitative Experience-Sampling Method. International Journal of Science and Mathematics Education, 17(3), 591-611. https://doi.org/10.1007/s10763-018-9879-x

Mata, M., Monteiro, V., \& Peixoto, F. (2012). Attitudes towards Mathematics: Effects of Individual, Motivational and Social Support Factors. Child Development Research, 2012, 1-10. https://doi.org/10.1155/2012/876028

Mauss, I., \& Robinson, M. (2009). Measures of emotion: A review. Cognition and Emotion, 23(2), 209-237. https://doi.org/10.1080/02699930802204677

McGrath, K., \& Van Bergen, P. (2017). Elementary teachers' emotional and relational expressions when sepeaking about disruptive and well behave students. Teaching and Teacher Education, 67, 487-497. https://doi.org/10.1016/j.tate.2017.07.016

Mullis, I., Martin, M., Foy, P., \& Arora, A. (2011). TIMSS 2011 International Results in Mathematics. Boston, EUA: TIMSS \& PIRLS International Study Center.

Muñiz, J. (1994). Classical Test Theory. Madrid: Pirámide. 
Nielsen, L., \& Kaszniak, A. (2007). Conceptual, theoretical, and methodological issues in inferring subjective emotional experience: Recommendations for researchers. In J. J. B. Allen \& J. Coan (Eds.), The Handbook of Emotion Elicitation and Assessment (pp. 361-375). Oxford University Press.

Norhoff, G. (2012). From emtoions to consciousness-A neuro-phenomenal and neuro-relational approach. Frontiers in Psychology, 3. https://doi.org/10.3389/fpsyg.2012.00303

Norman, G. (2010). Likert scales, levels of measurement and the "laws" of statistics. Advances in Health Sciences Education, 15(5), 625-632. https://doi.org/10.1007/s10459-010-9222-y

Nuria, I., Blanco, L., \& Guerrero, E. (2006). The affective domain in mathematics learning. International Electronic Journal of Mathematics Education, 1(1), 16-32.

OECD. (2016). PISA 2015. Key results. https://www.oecd.org/pisa/pisa-2015-results-in-focus-ESP.pdf

OECD. (2019). PISA 2018. Results. https://www.oecd.org/pisa/publications/PISA2018_CN_MEX_Spanish.pdf

Palacios, A., Arias, V., \& Arias, B. (2014). Attitudes towards mathematics: development and validation of an instrument for its meassurement. Revista de Psicodidáctica, 19(1), 67-91. https://doi.org/10.1387/RevPsicodidact.8961

Paoloni, P., \& Vaja, A. (2013). Achievement emotions in assessment contexts: an exploratory study with university students. Innovación Educativa, 13(62), 135-159.

Paoloni, P., Vaja, A., \& Muñoz, V. (2014). Realiability and validity of the Achievement Emotions Questionnaire. A study with Argentinean university students. Electronic Journal of Research in Educational Psychology, 12(34), 671-692. https://doi.org/10.25115/ejrep.34.14088

Peixoto, F., Mata, L., Monteiro, V., Sanches, C., \& Pekrun, R. (2015). The Achievement Emotions Questionnaire: Validation for pre-adolescent students. European Journal of Developmental Psychology, 12(4), 472-481. https://doi.org/10.1080/17405629.2015.1040757

Pekrun, R. (2006). The Control-Value Theory of Achievement Emotions: Assumptions, Corollaries, and Implications for Educational Research and Practice. Educational Psychology Review, 18(4), 315, 341. https://doi.org/10.1007/s10648-006-9029-9

Pekrun, R., \& Bühner, M. (2014). Self-report measures of academic emotions. In R. Pekrun \& L. Linnenbrink-Garcia (Eds.), Educational psychology handbook series (International handbook of emotions in education, pp. 561-579). Routledge/Taylor \& Francis Group.

Pekrun, R., \& Linnenbrink-Garcia, L. (2012). Academic Emotions and Student Engagement. In S. Christenson, A. Reschly \& C. Wylie (Eds.), Handbook of research on student engagement (pp. 259-282). Springer. https://doi.org/10.1007/978-1-4614-2018-7_12

Pekrun, R., Goetz, T., Frenzel, A., Barchfeld, P., \& Perry, R. (2011). Measuring emotions in students' learning and performance: The Achievement Emotions Questionnaire (AEQ). Contemporary Educational Psychology, 36(1), 36-48. https://doi.org/10.1016/j.cedpsych.2010.10.002

Pekrun, R., Hall, N., Goetz, T., \& Raymond, P. (2014). Boredom and academic achievement: Testing a model of reciprocal causation. Journal of Educational Psychology, 106(3), 696-710. https://doi.org/10.1037/a0036006

Pekrun, R., Lichtenfeld, S., Marxh, H., Murayama, K., \& Goetz, T. (2017). Achievement Emotions and Academic Performance: Longitudinal Models of Reciprocal Effects. Child Development, 88(5), 1653-1670. https://doi.org/10.1111/cdev.12704

Pekrun, R., Maier, A. M., \& Elliot, J. (2009). Achievement goals and achievement emotions: testing a model of their joint relations with academic performance. Journal of Educational Psychology, 101(1), 115-135. https://doi.org/10.1037/a0013383

Peterson, G. (2006). Cultural Theory and Emotions. In J. E. Stets \& J. H. Turner (Eds.), Handbook of the Sociology of Emotions (pp. 114-134). https://doi.org/10.1007/978-0-387-30715-2_6

Rodríguez, O., \& Mora, S. (2016). Psychometric analysis of the attitudes towards mathematics instrument using Samejima's Graded Response Model. Actualidades en Psicología, 30(120), 7-30. https://doi.org/10.15517/ap.v30i120.18722

Samejima, F. (1997). Graded response model. In W. Van der Linden \& R. Hambleton (Eds.), Handbook of modern item response theory (pp. 85-100). Berlin: Springer. https://doi.org/10.1007/978-1-4757-2691-6_5 
Sánchez, R. J., Becco, V., \& Marquez, F. (enero, 2011). ¿Cómo no voy a saber esto? Efectos y funciones de la vergüenza en clase [How I do not know this? Effects and functions of embarrassment in class]. III Congreso Internacional de Investigación y Práctica Profesional en Psicología XVIII. Retrieved from http://www.aacademica.com/000-052/526.pdf

Scherer, K. (2005). What are emotions? And how can they be measured? Social Science Information, 44(4), 695-729. https://doi.org/10.1177/0539018405058216

Steinberg, L. (2005). Cognitive and affective development in adolescence. Trends on Cognitive Science, 9(2), 69-74. https://doi.org/10.1016/j.tics.2004.12.005

Suberviola-Ovejas, I. (2011). Competencia emocional y rendimiento académico en estudiantes universitarios [Emotional competence and academic achievement in university students]. Vivat Academia, 117, 1-17. Retrieved from https://www.redalyc.org/pdf/5257/525752959006.pdf

Turner, J. C., \& Trucano, M. (2014). Measuring situated emotion. In R. Pekrun \& Linnenbrink-Garcia (Eds.), International handbook of emotions in education. Taylor \& Francis.

Valiente, J., \& Swanson, N. (2012). Linking Students' Emotions and Academic Achievement: When and Why Emotions Matter. Child Development Perspectives, 6(2), 129-135. https://doi.org/10.1111/j.1750-8606.2011.00192.x

Van Petegem, P., Deneire, A., \& De Maeyer, S. (2008). Evaluation and participation in secondary education: Designing and validating a self-evalluation instrument for teachers to solicit feedback from pupils. Studies in Educational Evaluation, 34, 136-144. https://doi.org/10.1016/j.stueduc.2008.07.002

Villavicencio, F., \& Bernardo, A. (2015). Beyond Math Anxiety: Positive Emotions Predict Mathematics Achievement, Self-Regulation, and Self-Efficacy. The Asia-Pacific Education Researcher, 25, 415-422. https://doi.org/10.1007/s40299-015-0251-4

Williams, B., Onsman, A., \& Brown, T. (2010). Exploratory factor analysis: A five-step guide for novices. Journal of Emergency Primary Health Care, 8(3), 1-13. https://doi.org/10.33151/ajp.8.3.93

Yamac, A. (2014). Classroom Emotions Scale for Elementary School Students (Ces-Ess). Mevlana International Journal of Education, 4(1), 150-163. Taylor \& Francis. https://doi.org/10.13054/mije.13.72.4.1

Zan, R., Brown, L., Evans, J., \& Hannula, M. (2006). Affect in Mathematics Education: An Introduction. Educational Studies in Mathematics, 63(2), 113-121. https://doi.org/10.1007/s10649-006-9028-2

Zeldin, A., Britner, S., \& Pajares, F. (2007). A comparative study of the self-efficacy beliefs of successful men and women in mathematics, science, and technology careers. Journal of Research in Science Teaching, 45(9), 1036-1058. https://doi.org/10.1002/tea.20195

Zullig, K., Koopman, T., Patton, J., \& Ubbes, V. (2010). School Climate: Historical Review, Instrument Development and School Assessment. Journal of Psychoeducational Assessment, 28(2), 139-152. https://doi.org/10.1177/0734282909344205

\section{Appendix A}

Inventory of Emotions Experienced by Adolescents When Solving Mathematical Tasks (INETAM, For Its Initials in Spanish). Translated to English

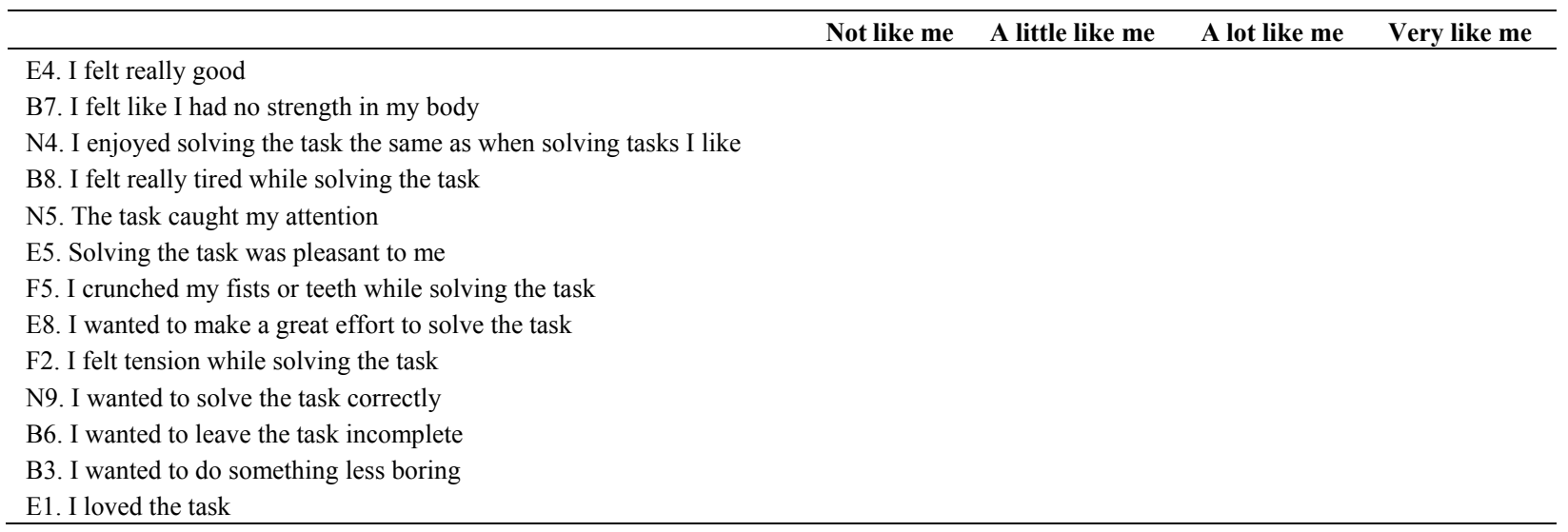


N3. The task made me feel good

N8. I made an effort to understand what I had to do

E2. I felt very happy while solving the task

F1. The task made me feel frustration

N6. I set out to solve the task correctly

E7. I wanted more time to continue solving the task

N2. I enjoyed solving the task

B9. I felt completely without energy

N10. I experienced enough energy to solve the task

F3. I felt a knot in my stomach while solving the task

F8. I felt the urge to hit or throw something while solving the task

F4. I had the urge to do something to stop feeling so bad

B4. I wanted to fall asleep

N1. I realized I was enjoying solving the task

B5. Others may have noticed I was bored

N7. I set out to solve the whole task

F6. I wished I was solving an easier task

F7. I experienced unpleasant sensations in my body

E6. I wanted to know the right result

B1. I felt bored while solving the task

B2. Solving the task made me feel weak

E3. I experienced a lot of energy while solving the task

\section{Copyrights}

Copyright for this article is retained by the author, with first publication rights granted to the journal.

This is an open-access article distributed under the terms and conditions of the Creative Commons Attribution license (http://creativecommons.org/licenses/by/4.0/). 